\title{
Ultra-Compact High-Efficiency Luminaire for General Illumination
}

\author{
Final Report
}

Period Start Date:

Period End Date:

Principal Investigator:

Date Report Issued:

Award Number:

Project Manager:
February 26, 2010

April 8, 2012

Ted Lowes

June 28, 2012

DE-EE0003246

Clark Robinson

Cree Santa Barbara Technology Center

340 Storke Road

Goleta CA 93117

(805) 968-9460 


\section{ABSTRACT}

Cree has developed a new ultra-compact light emitting diode (LED) luminaire capable of providing high efficacy with excellent color quality that can lead to significant energy savings in today's commercial and retail applications. This success was based on an integrated development effort tailoring the LED component characteristics, optics, thermal management and driver design for the small footprint to achieve an overall system efficiency of $\geq 70 \%$.

A new LED component was designed to provide high brightness and efficacy in a form factor that allowed for a small directional beam with a luminaire housing design able to dissipate the heat effectively using a small physical envelope. A very compact, $90 \%$ efficient driver was developed to meet the system performance while not taking away any thermal mass from the heat sink. A 91\% efficient secondary optics was designed to maximize efficiency while providing a smooth beam. The reliability of the new LED component was robust under accelerated testing conditions. Luminaires were assembled integrating the novel LED component, secondary optics, heat sink and driver technology to demonstrate the system improvement.

Cree has successfully completed this project by developing an ultra-compact LED luminaire that provided 380 lumens at a correlated color temperature (CCT) of $2822 \mathrm{~K}$ and color rendering index (CRI) of 94 with an efficacy of 94 lumens per watt (LPW) when operating at 4 W input power (steady state) with an overall system efficiency of $81 \%$. At a higher input power of 9 Watts, the lamp provided 658 lumens at 71 LPW. 


\section{DISCLAIMER}

This report was prepared as an account of work sponsored by an agency of the United States Government. Neither the United States Government nor an agency thereof, nor any of their employees, makes any warranty, express or implied, or assumes any legal liability or responsibility for the accuracy, completeness, or usefulness of any information, apparatus, product, or process disclosed, or represents that its use would not infringe privately owned rights. Reference herein to any specific commercial product, process, or service by trade name, trademark, manufacturer, or otherwise does not necessarily constitute or imply its endorsement, recommendation, or favoring by the United States Government or any agency thereof. The views and opinions expressed herein do not necessarily state or reflect those of the United States Government or any agency thereof. 
$\underline{\text { Table of Contents }}$

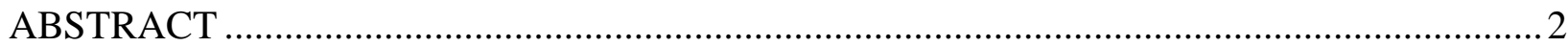

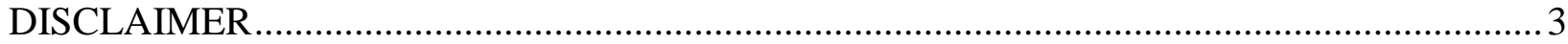

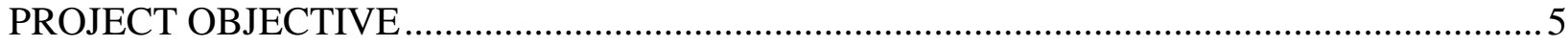

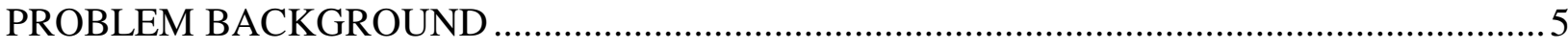

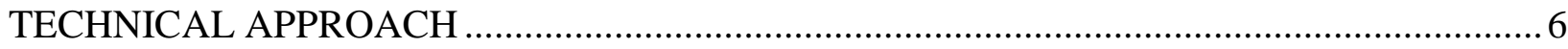

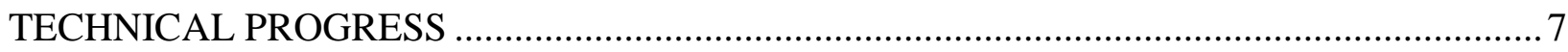

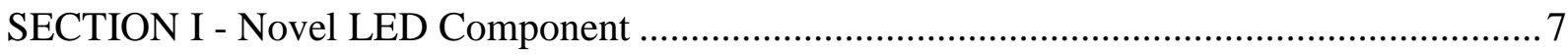

Component Design and Fabrication ................................................................. 7

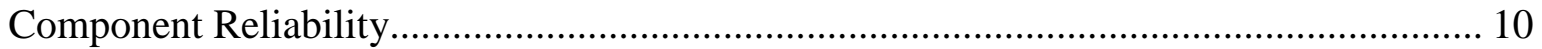

SECTION II - Luminaire Housing with Integrated Thermal and Optics .............................. 11

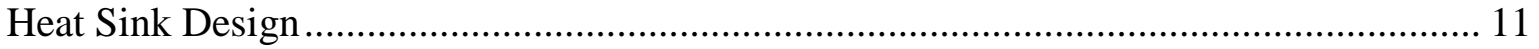

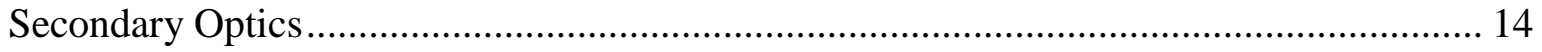

SECTION III - Compact Driver Development........................................................... 16

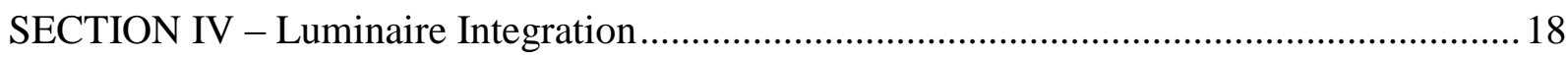

TECHNOLOGY COMMERCIALIZATION .................................................................. 19

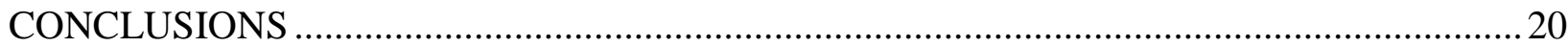




\section{PROJECT OBJECTIVE}

Cree is developing an ultra-compact 80 lumen per watt (LPW) light emitting diode (LED) luminaire that emits white light at a correlated color temperature (CCT) of 3000K with a CRI of 90. By the end of the program, Cree aims to demonstrate efficient warm white LED luminaire product prototypes that maintain high performance at 'real-life' operating conditions. This development will enable significant site energy savings by initially targeting retail and commercial applications, which are most sensitive to the lifetime operating costs.

To achieve this objective, Cree plans to build on its high brightness LED platform to design a novel LED component that will enable an ultra-compact LED luminaire with a high system efficacy. The project will involve synergetic LED component, optics, thermal management and driver developments to enable the specified luminaire performance.

The ultimate goal was to deliver to the Department of Energy a proof-of-concept warm-white ultra-compact luminaire prototype that produces 320 lumens at a CCT of $3,000 \mathrm{~K}$ and a CRI > 90 with an efficacy of 80 LPW.

This report contains a summary of technical progress made during the two year project.

\section{PROBLEM BACKGROUND}

Solid-state LEDs have emerged as the long-term, cost-effective and environmentally-friendly alternative for inefficient conventional lighting, by combining one or more saturated color LEDs with a phosphor or other light down-converting media to achieve lighting-class white broadband illumination. In spite of the short bulb life, lack of robustness and low overall efficiency of 8-20 LPW associated with incandescent and halogen lighting, it has became entrenched due to the extremely low cost (low dollars per lumen and initial cost) and historical infrastructure of the fixture design. To become viable, energy efficient replacement solutions must deliver system efficacies of $\geq 80$ lumens per watt (LPW) with excellent color rendition (CRI $\geq 90$ ) at a cost that enables payback cycles of 2-3 years for commercial lighting.

To improve the luminaire system efficiency, a comprehensive, integrated development effort is needed. Without an integrated development effort, it is unlikely the optics, thermal and driver technology will arrive independently to achieve these goals. For example, there exists a tradeoff between compact source sizes for tight beam angles and thermal management in an ultracompact geometry. When you optimize the optical source size, there is a detriment to the thermal management and vice versa. This, in turn, puts further restrictions on the driver size since most of the physical lamp housing is needed for heat sinking. Many of these such trade- 
offs exist to maximize system performance and efficiency, thus necessitating a holistic design where the subsystems must be designed in tandem.

These challenges were the reason that ultra-compact LED luminaire performance at the start of the project was subpar. Typical products available at that time provided, at best, efficacies of 50 LPW and flux up to 300 lumens. In light of these challenges, Cree aimed to develop an ultracompact SSL luminaire using synergetic LED component, optics, thermal management and driver developments to enable $80 \mathrm{LPW}$ at a color temperature of $3000 \mathrm{~K}$ with a CRI $>90$.

\section{TECHNICAL APPROACH}

To achieve this objective, Cree leveraged the synergy of its high efficiency LED component technology and expertise in luminaire thermal management, optics and driver electronics to achieve the goals of this program. A key to project success was managing the many interdependencies of the various subsystems - LEDs, optics, thermal and driver - and their resulting trade-offs. Some fundamental trade-offs exist between the various subsystems, such as thermal and optical design considerations for LED-based luminaires. Cree focused on balancing the various tradeoffs to create an efficient luminaire system.

The project built on Cree's expertise in LED packaging technology using its high brightness XLamp ${ }^{\circledR}$ LED component platform to design the novel LED component with high flux and efficacy optimized for the compact luminaire. The trade-off between optics (small source size for tight beam angles) and thermal management (larger chip spacing more efficient) were investigated through optical and thermal modeling. The package was designed to maintain a low thermal resistance through novel substrate designs that remove the heat from the chip more effectively. The new package design and processes were developed to be compatible with Cree's evolving high-speed SSL component manufacturing lines. Cree conducted studies to investigate the reliability of the new LED components. The materials and fabrication processes used were examined to ensure they perform under accelerated testing conditions.

Cree designed a lamp housing with integrated optics and thermal management. Optical modeling was used to optimize the optic in tandem with the LED component dimensions to provide the necessary performance level. Thermal modeling was performed to design the heat sink to provide the overall thermal resistance criteria for the lamp. The system integration processes like component attach to the heat sink was designed to maintain a low thermal resistance at the system level. Scaled models of select approaches were fabricated and tested to provide iterative feedback for this portion of the project.

Cree designed an efficient, ultra-compact low voltage driver to fit in the small cavity for the 
control electronics. The driver was designed in parallel with the chip component to develop the proper driver topology with the corresponding chip count. After initial design testing, the driver circuitry and various discrete elements were integrated into a custom power supply.

\section{TECHNICAL PROGRESS}

\section{SECTION I - Novel LED Component}

\section{Component Design and Fabrication}

The component design is determined by the ultra-compact luminaire optics and thermal management trade-offs and must enable an efficient driver topology. For instance, narrow beam profiles require the LEDs to be placed as close together as possible, though there is a significant thermal penalty paid for closely spaced arrays.

Cree has assessed the trade-offs associated with different approaches for the LED component design. The various factors that were considered for the component design include:

- Component design will depend on secondary optics geometry - small source size

- Component will provide low thermal resistance using novel substrate designs that remove the heat from the chip more effectively

- Component design will be mindful of chip count design rules for driver electronics

- Materials and fabrication processes must be robust to ensure long component chips 1000 hours reliability testing

During the first year of the project, Cree evaluated the chip count and chip size that would provide the appropriate flux and efficiency from a small component footprint needed for the lamp design. The chip count and operating conditions (drive current \& voltage) will also impact the thermal design of the component and the driver topology. These factors

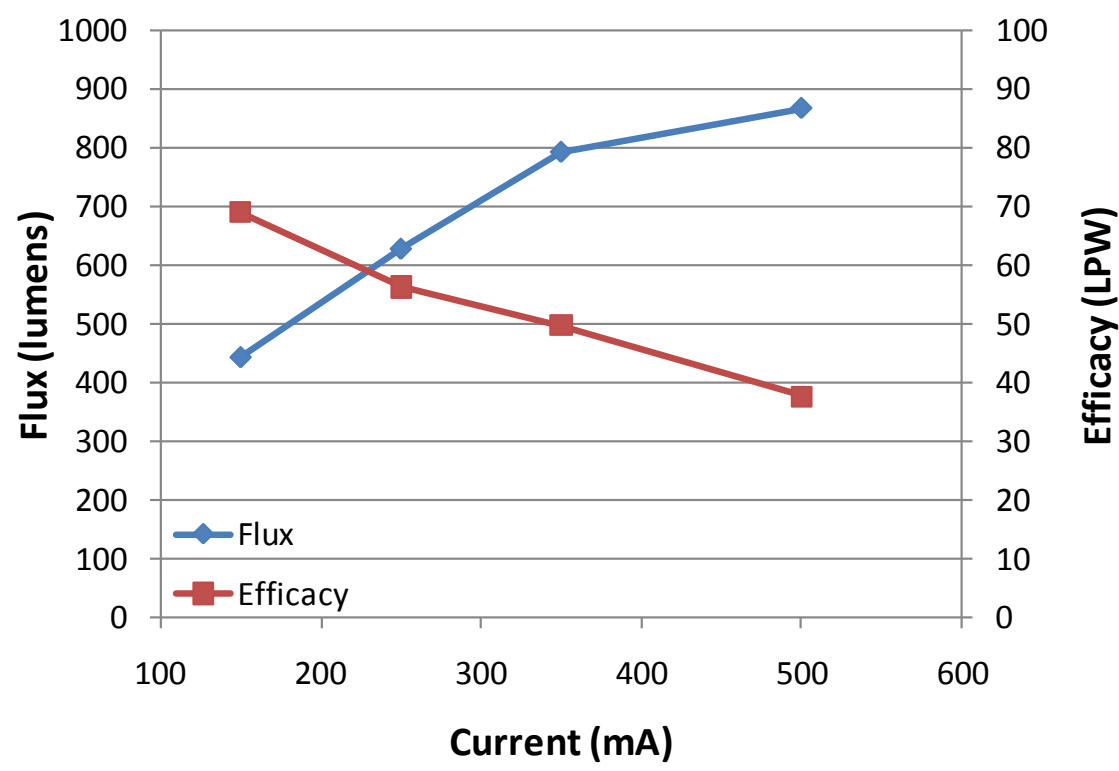

Figure 1: First generation LED component's flux and efficacy characteristics as a function of drive current. This component serves as the baseline for improvement. 
were considered in the overall design to reach the milestone of a $1{ }^{\circ} \mathrm{C} / \mathrm{W}$ component thermal resistance while remaining within the maximum optical source size for a narrow luminaire beam angle.

Generation 1 Component Design: Cree successfully assembled a first generation component prototype to serve as a baseline using Cree's currently available technology at the start of the project. It has a small optical source size suitable for the required beam angles of 20-40 degrees in the lamp geometry. This component generated more than 400 lumens at an efficacy of 69 LPW. The flux and efficacy as a function of current are shown in Figure 1.

During the course of the first year, Cree has improved upon its Generation 1 component prototype. This improved version of the component generates 494 lumens at an efficacy of 89.6 LPW and $3050 \mathrm{~K}$ color temperature under steady-state operation (see Figure 2). This exceeds the Year 1 milestone for a white LED component providing 300 lumens at 85 LPW, 3000K and $\mathrm{Tj}=25^{\circ} \mathrm{C}$.

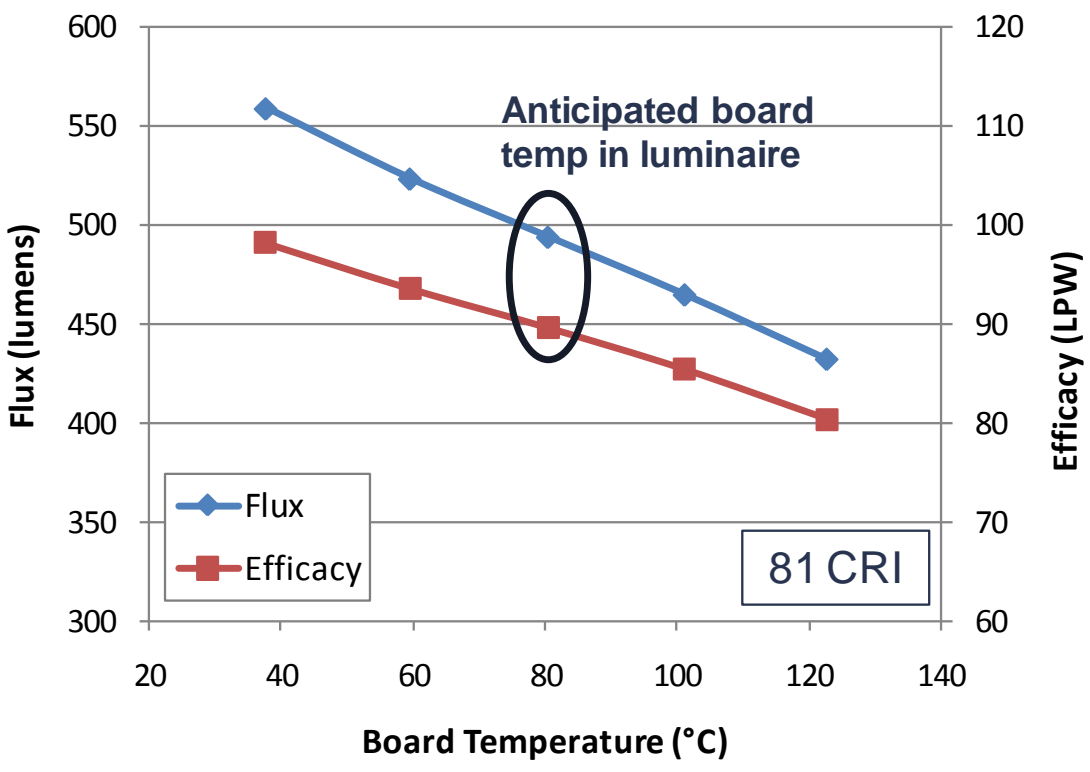

Figure 2: Improvements to the Generation 1 component led to higher flux and efficacy characteristics. Under steady state operation the component provides 494 lumens and 89.6 LPW at $3050 \mathrm{~K}$ and $80 \mathrm{CRI}$. This demonstration meets the Year 1 component milestone.

\section{Low Thermal Resistance:}

An optimized thermal design is essential since the compact luminaire envelope provides a significant challenge for heat dissipation. Cree has focused on improving the thermal design of the LED component to minimize the overall requirements of system thermal resistance. To achieve the desired beam profiles for a compact luminaire, it is necessary to place the LED chips as close together as possible, though, from a thermal design standpoint, close spacing of the multiple LED chips on a heat sink is results in a higher thermal resistance. Removing this excess heat is one of the critical issues associated with improving performance and viability of LED-based lighting, since heat build-up leads to increased LED junction temperature and a corresponding decrease in LED efficiency as well as phosphor conversion efficiency. Further, 
heat flow out of the system should be independent of lamp orientation, and allow efficient operation in ambient temperatures as high as $65^{\circ} \mathrm{C}$ for recessed ceiling mounted fixtures.

Cree has developed a new component platform with improved thermal resistance. Component prototypes were fabricated using this new platform which resulted in a thermal resistance from junction to board of $0.76^{\circ} \mathrm{C} / \mathrm{W}$ - a $30 \%$ improvement over the standard platform (XLamp LED components attached to a metal-core printed circuit board). This met the Year 1 milestone of an LED component with a thermal resistance of $1^{\circ} \mathbf{C} / \mathbf{W}$. When mounted on a heat sink, this thermal resistance improvement can lead to an $8^{\circ} \mathrm{C}$ junction temperature reduction at an input power of $5 \mathrm{~W}$ (expected for the final luminaire).

Generation 2 Component Design: While the performance of the Generation 1 LED component had decent flux and efficacy performance, the CRI is only 81 . The next generation components must have a higher CRI, which can lower the resulting efficacy. The focus during the second year was improving the CRI to 90 while simultaneously increasing the efficacy to reach the final project goals. In addition, Cree integrated the new thermal platform within the component design to improve the thermal resistance to $1^{\circ} \mathrm{C} / \mathrm{W}$ compared to $2^{\circ} \mathrm{C} / \mathrm{W}$ for the Generation 1 component.

The Generation 2 component generated 324 lumens at an efficacy of 89 LPW and CCT of $2686 \mathrm{~K}$ with a 93 CRI (Figure 3). This exceeded the Year 1 milestone for a white LED component providing 300 lumens at 85 LPW, 3000K

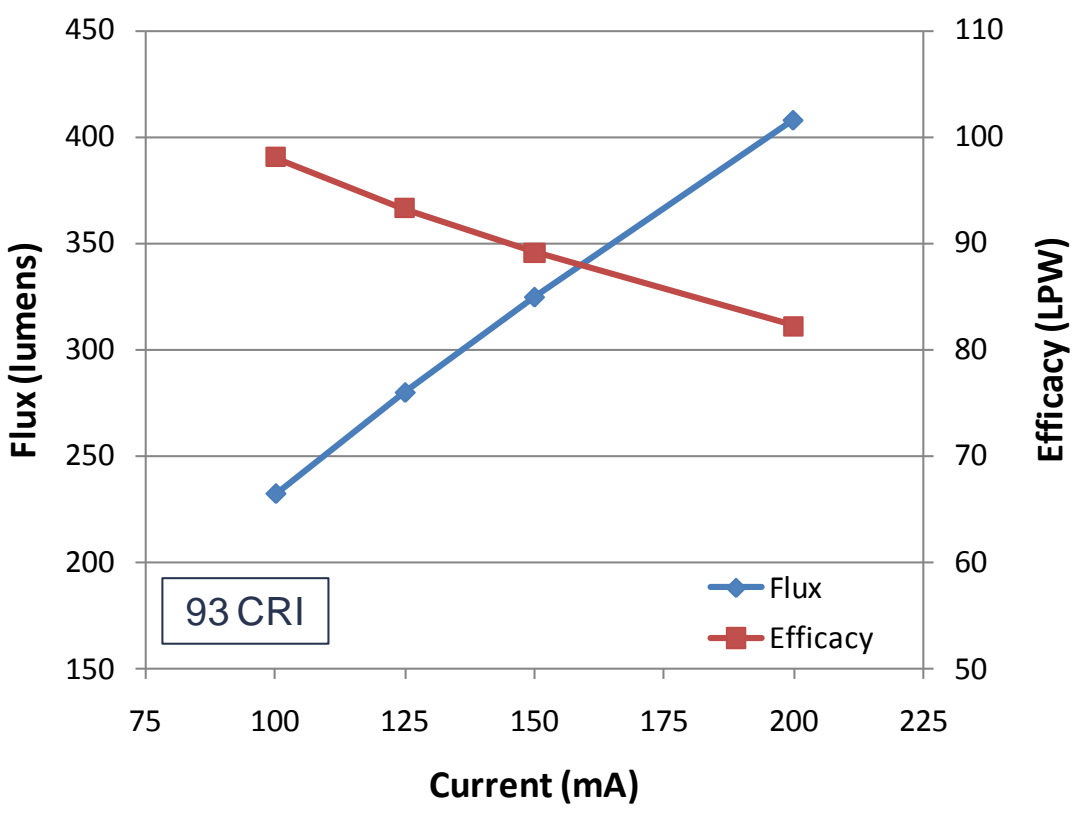

Figure 3: The Generation 2 component led to higher efficacy characteristics and CRI, providing 324 lumens at an efficacy of $89 \mathrm{LPW}$ and CCT of $2686 \mathrm{~K}$ with a $93 \mathrm{CRI}$. This exceeded the Year 1 milestone for a white LED component providing 300 lumens at $85 \mathrm{LPW}, 3000 \mathrm{~K}$ and $\mathrm{Tj}=25^{\circ} \mathrm{C}$. and $\mathbf{T j}=25^{\circ} \mathrm{C}$.

Generation 3 Component Design: Cree has successfully assembled its Generation 3 component prototype with improved efficacy and CRI. This component generated 430 lumens at an efficacy of 124 LPW and CCT of $2816 \mathrm{~K}$ with a CRI of 94 (Figure 4). This performance 
exceeded the Year 1.75

milestone for a white LED component providing 400 lumens at $114 \mathrm{LPW}, 3000 \mathrm{~K}$

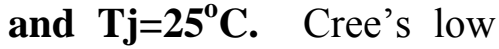
thermal resistance component platform was also integrated into this third generation design. The spectral efficiency of this component is 345 lumens per optical watt exceeding the Year 1.5 milestone for a component with a 330 lumen per optical watt spectral efficiency.

The LED component

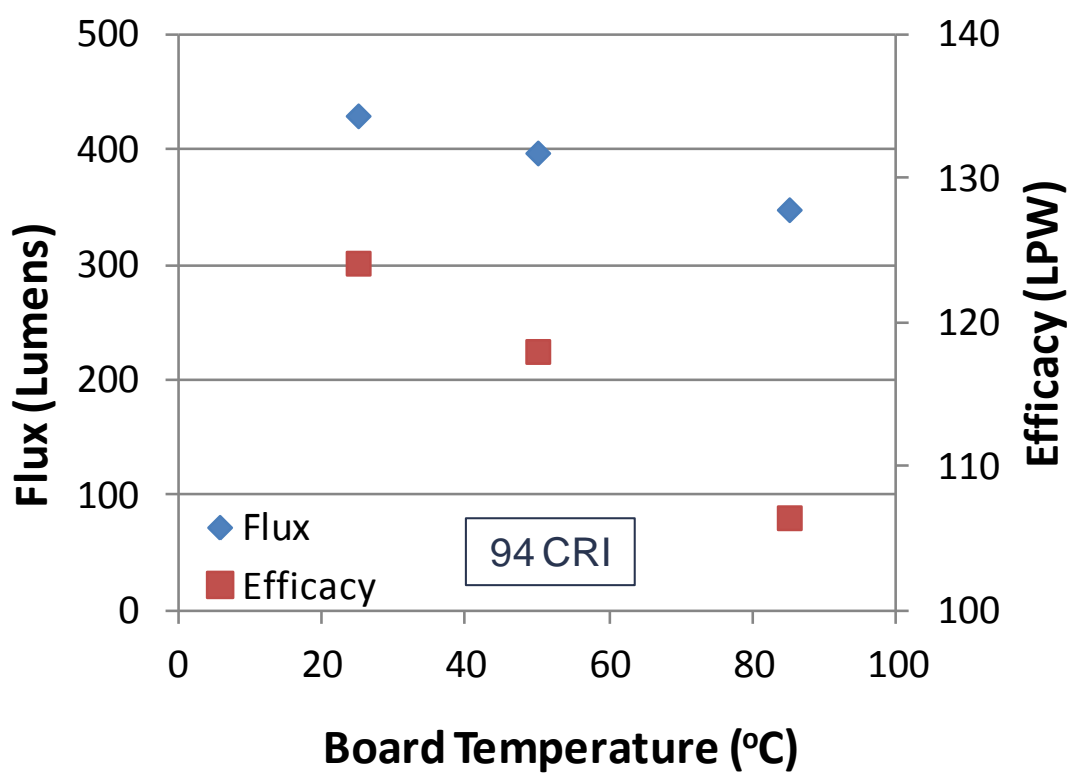

Figure 4: Third generation MR16 component's flux and efficacy characteristics as a function of board temperature. At $25^{\circ} \mathrm{C}$, the component generates 430 lumens at $2816 \mathrm{~K}$ with a CRI of 94 and efficacies up to 124 LPW. At the higher board temperature of $85^{\circ} \mathrm{C}$, the component provides 350 lumens at an efficacy of 106 LPW.

provided over 350 lumens at

$106 \mathrm{LPW}$ when operating at a board temperature of $85^{\circ} \mathrm{C}$. The flux and efficacy as a function of board temperature is shown in Figure 4.

\section{Component Reliability}

Cree performed reliability testing on the LED components to ensure the new materials and fabrications steps would perform consistently over its lifetime. As with any new package design, long term reliability is a key metric. This is especially true for luminaire products where the expectation is for 50,000 hours of operation.

Accelerated environmental testing was performed using industry-standard test methods for stressed conditions (high temperature and high humidity). The LEDs are checked for changes in luminous flux, changes in color point, increases in forward voltage and increases in forward leakage at various intervals throughout the wet high temperature operating life (WHTOL) testing. The reliability goal was to achieve greater than $90 \%$ lumen maintenance after 1000 hours under WHTOL tests.

Cree has demonstrated its Generation 3 component (with two independent strings) to achieve 95\% lumen maintenance after 2016 hours of high temperature, high humidity testing with a color shift less than 0.005 in delta u'v' (Figure 5). This exceeds the Year 1.9 milestone for an 
LED component with greater than $90 \%$ lumen maintenance after 1000 hours stressed testing.

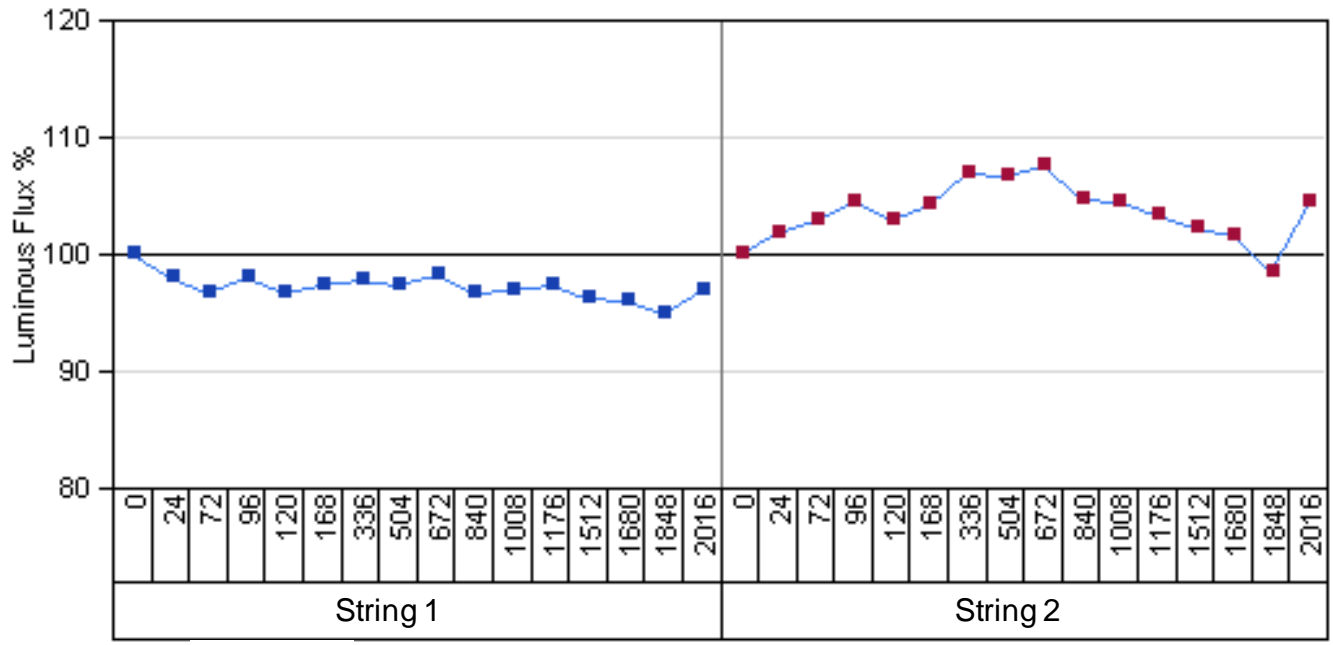

Hours

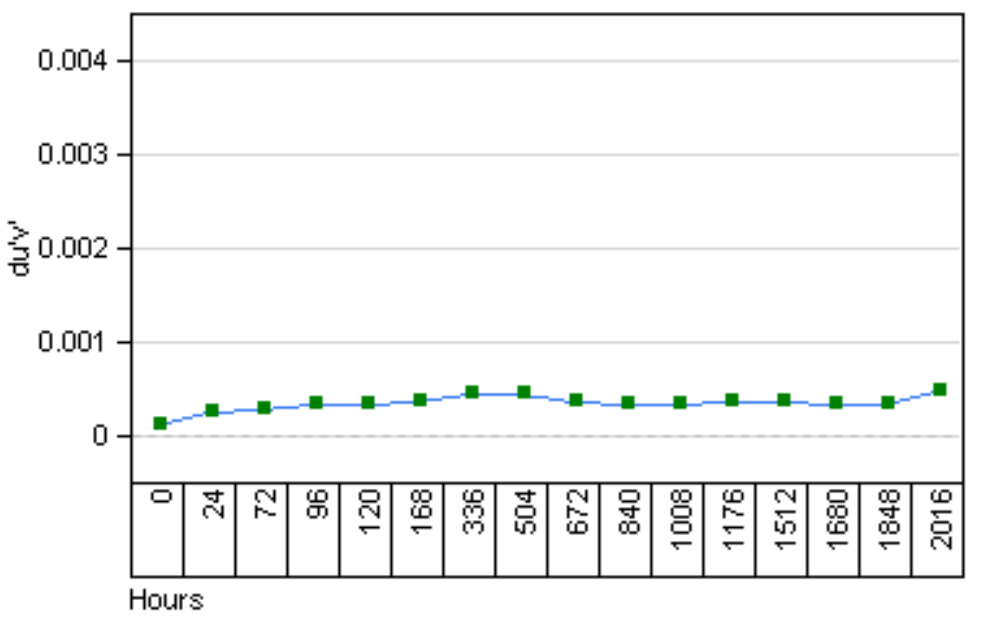

Figure 5: Normalized mean luminous flux (top) and color point shift (bottom) observed during 2016 hours wet high temperature operating life testing is shown for prototype generation 3 LED components. The lumen maintenance remains $>95 \%$ and the color shift is less than 0.005. This exceeds the Year 1.9 milestone of $>90 \%$ lumen maintenance after 1000 hours stressed testing. This preliminary data indicates the ability to maintain low color shift and high lumen maintenance with the component design.

\section{SECTION II - Luminaire Housing with Integrated Thermal and Optics}

The mechanical assembly of the luminaire performs several functions:

- Beam shaping - integrated optics provide the desired beam profile of the lamp,

- Heat sinking - dissipating heat generated by the LED devices,

- Housing the driver electronics

\section{Heat Sink Design}

Cree has assessed various heat sink designs for the compact luminaire. As mentioned earlier, removing the excess heat is one of the critical issues associated with improving the performance in LED lighting. The problem is more of a challenge in a compact physical envelope due to the 
small space available for a heat sink and the small optical source size (requiring closer packed LED arrays) needed for narrow beam angles. The trade-off involves the amount space dedicated to the heat sink versus the secondary optics in the physical envelope. If the depth of the optics is not large enough, the light that does not hit the lens will exit directly at a very wide beam angle creating an undesired halo-effect. In addition to the performance requirements, a cost-effective, manufacturable heat sink is essential.

Cree evaluated the performance of various heat sink designs using thermal modeling and thermal resistance measurements made on the heat sinks themselves. System integration processes, like component attach to the heat sink, were also optimized for a low thermal resistance at the system level. The results on four different heat sinks evaluated in Year 1 are shown in Table 1. Heat sink $\mathrm{C}$ had the lowest thermal resistance and also the largest opening for the secondary optics.

Table 1: Modeled and measured thermal resistance values from heat sink to ambient for four different heat sinks. The thermal modeling correlated with the measured thermal resistance values for the first two heat sinks. Heat sink A allowed Cree to reach the Year $\mathbf{0 . 7 5}$ milestone of $8^{\circ} \mathrm{C} / \mathrm{W}$ junction to ambient thermal design. Heat sink $\mathrm{C}$ will only improve it.

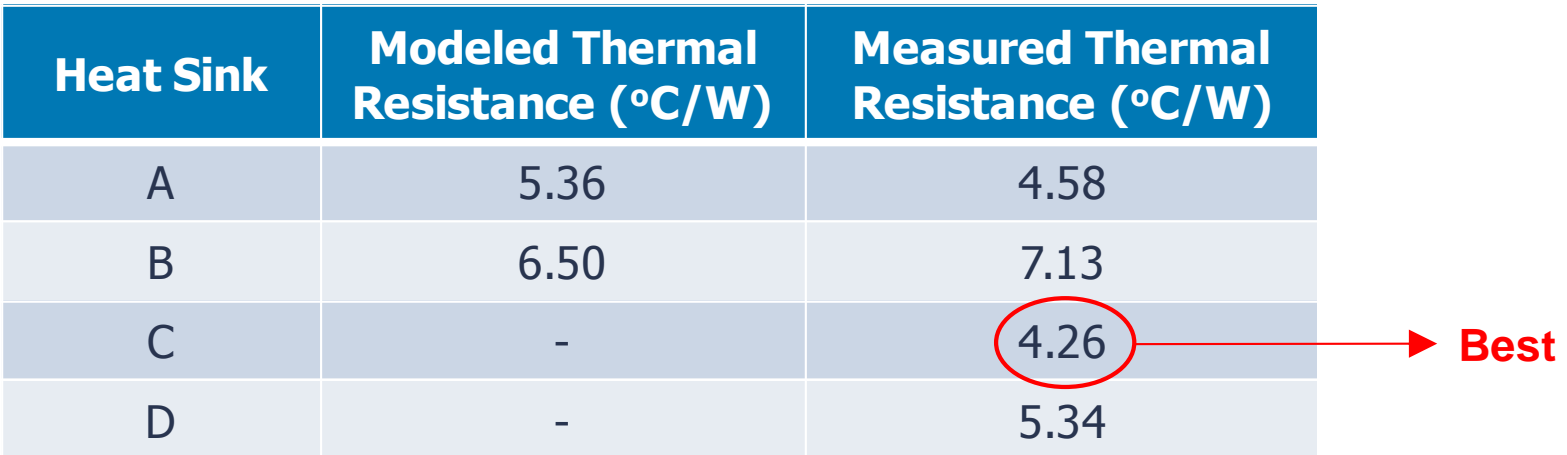

Thermal Resistance of the System: Removing the excess heat from the LEDs is one of the critical challenges in a compact luminaire envelope due to the small space available for a heat sink. Cree has characterized the system level thermal resistance of the compact luminaire using the low thermal resistance LED component assembled on heat sink A. (Note: heat sink C was not designed at the time of this experiment.)

The system thermal resistance is the total series resistances from the junction to the solder point (Rth j-sp), from the solder point to the heat sink (Rth sp-h) and from the heat sink to ambient (Rth h-a) described in the following relationship:

$$
R_{\text {th j-a }}=R_{\text {th j-sp }}+R_{\text {th sp-hs }}+R_{\text {th hs-a }}
$$


The compact luminaire has a measured thermal resistance of $7.91^{\circ} \mathrm{C} / \mathrm{W}$ from junction to ambient; the thermal resistance of the heat sink was $4.70^{\circ} \mathrm{C} / \mathrm{W}$. Note: this system does not contain heating power from the driver (which was installed in the lamp cavity as a thermal load but not powered on). This system met the Year 0.75 milestone of an $8^{\circ} \mathrm{C} / \mathrm{W}$ junction-toambient thermal design for the luminaire prototype.

\begin{tabular}{|c|c|}
\hline $\begin{array}{c}\text { Compact } \\
\text { Luminaire }\end{array}$ & $\begin{array}{c}\text { Thermal Resistance } \\
(\mathbf{C} / \mathbf{W})\end{array}$ \\
\hline Rth j-a & 7.91 \\
\hline Rth j-sp & 1.82 \\
\hline Rth sp-hs & 1.39 \\
\hline Rth hs-a & 4.70 \\
\hline
\end{tabular}

Table 2: Measured thermal resistance values from junction-to-ambient and heat sink-to-ambient for a compact luminaire using the low thermal resistance LED component. This result reached the Year 0.75 milestone of $8^{\circ} \mathrm{C} / \mathrm{W}$ junction to ambient thermal design and provides a good springboard toward the overall goal of $5^{\circ} \mathrm{C} / \mathrm{W}$.

During the project's second year, quick feedback thermal resistance measurements were performed and compared to the previous heat sink designs. For the quick feedback measurements, the thermal resistance is measured from LED solder point to ambient for the varying heat sink designs, which are assembled with optics and driver to give an accurate measure of system performance (minus the LED thermal resistance).

Year 2 heat sink designs ( $\mathrm{G}, \mathrm{H}, \mathrm{I}$, and $\mathrm{J}$ ) provided a low thermal resistance of $6.0-6.4^{\circ} \mathrm{C} / \mathrm{W}$ (solder point-to-ambient), which was in line with the better heat sink designs previously explored. The designs evaluated included varying fin spacing, base plate thickness, cut slots in base plates and high emissivity coatings. Table 3 below summarizes the quick thermal resistance measurements of the better heat sink designs over the course of the project. Heat sink $\mathrm{G}$ provided the best system thermal resistance when assembled with the Gen 3 LED component $-6.0^{\circ} \mathrm{C} / \mathrm{W}$ from solder point to ambient.

\begin{tabular}{|c|c|}
\hline Heat Sink & $\begin{array}{c}\text { Thermal Resistance (C/W) } \\
\text { Solder point to ambient }\end{array}$ \\
\hline C & 6.1 \\
\hline E & 7.3 \\
\hline G & 6.0 \\
\hline H & 6.4 \\
\hline I & 6.3 \\
\hline J & 6.2 \\
\hline
\end{tabular}

Cree assembled its best heat sink and component thermal design to date in order to ascertain the system thermal resistance. Cree has achieved a thermal resistance of $7.26^{\circ} \mathrm{C} / \mathrm{W}$ from junction to ambient, which is

Table 3: Quick feedback thermal resistance values from solder-point-to-ambient for a compact luminaire using the low thermal resistance LED component. Heat sink G provided the best thermal resistance of $6.0^{\circ} \mathrm{C} / \mathrm{W}$ from solder-point-to-ambient. 
significantly reduced from the beginning of the project (in the range of $10-12^{\circ} \mathrm{C} / \mathrm{W}$ ). The component portion of the thermal resistance is $0.90^{\circ} \mathrm{C} / \mathrm{W}$ while the board attach and heat sink contributes an additional $6.36^{\circ} \mathrm{C} / \mathrm{W}$ (also known as solder point to ambient). Cree has measured thermal resistances for solder point to ambient as low as $6.0^{\circ} \mathrm{C} / \mathrm{W}$ for this heat sink design but it did not occur for this particular system assembly. This assembly missed the Y1.5 milestone of $5^{\circ} \mathrm{C} / \mathrm{W}$ junction-to-ambient, but the heat sink does provide sufficient thermal management for the luminaire prototype to meet the final performance milestones.

\section{Secondary Optics}

Optical modeling was used to determine optimal lens design. The LED component dimensions are being optimized in tandem with the secondary optic to provide the necessary performance level. Cree has examined a number of different secondary optic designs to fit within the heat sink and luminaire physical envelope. The secondary optics will consist of a highly efficient lens to collimate the light from the LED to the desired beam angle. The LED

Table 4: The optical efficiency of four different secondary optics, with beam angles ranging from 17 to 37 degrees, was measured. These optics had efficiencies greater than $80 \%$

\begin{tabular}{|c|c|c|}
\hline Optics & $\begin{array}{c}\text { Beam } \\
\text { Angle }\left({ }^{\circ}\right)\end{array}$ & $\begin{array}{c}\text { Efficiency } \\
(\%)\end{array}$ \\
\hline A & 30.6 & 84 \\
\hline B & 37.0 & 94 \\
\hline C & 17.6 & 90 \\
\hline D & 25.6 & 88 \\
\hline
\end{tabular}

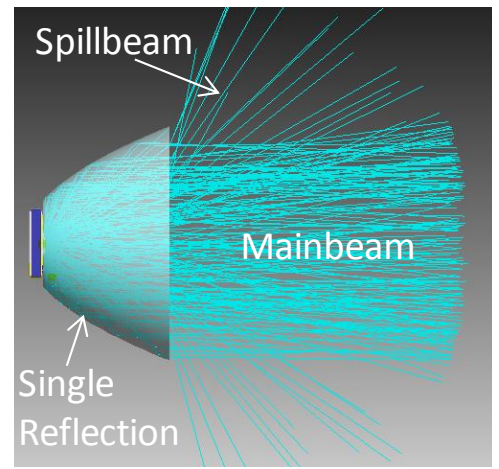

Figure 6: Optical simulation showing a lens collimating light from an LED source. The light that does not get collimated by the lens into the desired beam angle exits at a wide beam angle, which creates creating a spill-beam (i.e. a halo around the main beam).

component dimensions will be optimized in tandem with the optic to provide the necessary performance level. The ultimate goal is to develop a manufacturable, high efficiency (88-90\%) design that provides a beam angle between $20-40^{\circ}$.

Various optics were characterized for efficiency and beam quality. The results of four promising optics designs are compared in Table 4 and Figure 7. The beam profile was measured using a goniophotometer, which determines the spatial radiation pattern over the entire forward hemisphere of the lamp. The optical efficiency was measured using an integrating sphere.

A trade-off can exist between efficiency and beam quality. Optic A showed a nice beam 
profile with a beam angle of $30.6^{\circ}$ and very low spill over into high angles. The efficiency was $84 \%$, a good first result. Optic B showed a higher efficiency of $94 \%$ though the quality of its beam profile was not as good as Optic A. It has a larger "spill-beam" of light, that is, the light that exits at higher angles than the desired beam angle. This spill beam, shown schematically in Figure 6, is undesirable since it forms a halo around the main beam (i.e. an effect often seen in flashlights). Optics $\mathrm{C}$ and $\mathrm{D}$ designs had high optical efficiencies in combination with good beam quality. (Note: $\mathrm{C}$ and D had a similar optical design but were tailored for two different beam angles.)

To further assess what is required in the beam profile, a number of halogen lamps were characterized. The halogen lamps also exhibit some spill over with high angle light.

Several representative halogen

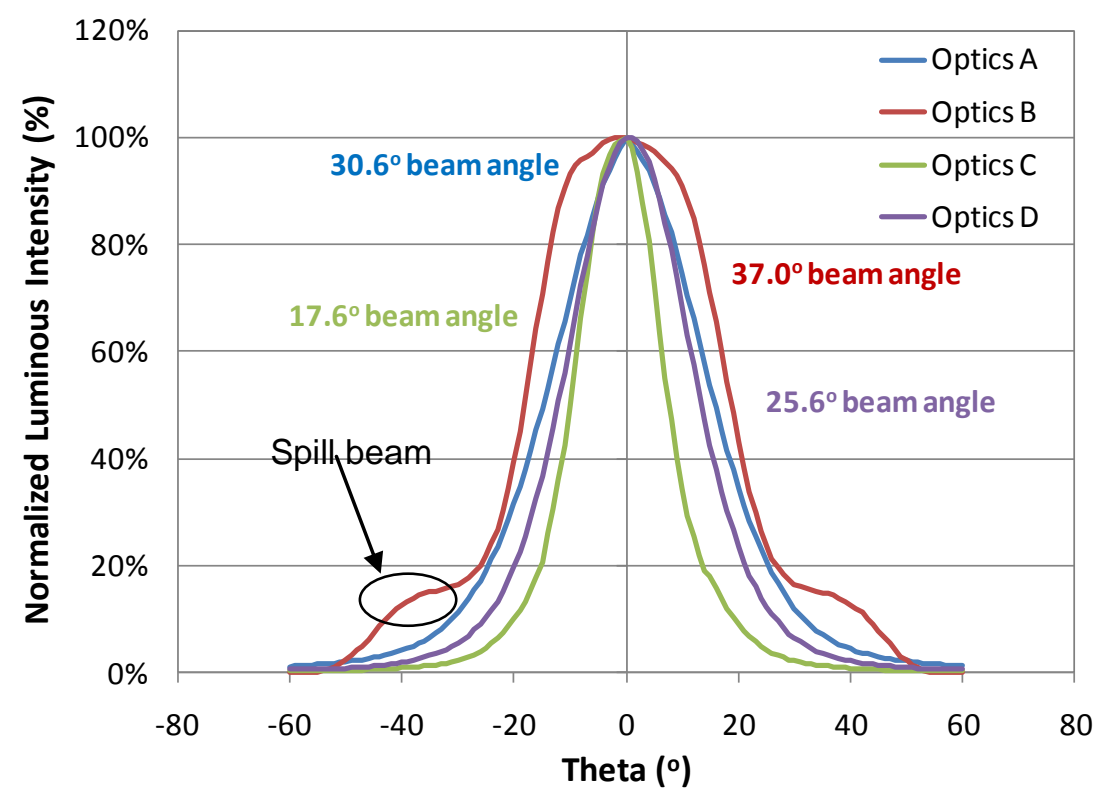

Figure 7: The relative luminous intensity of four secondary optics is shown as a function. Optics $A, C$ and $D$ shows a nice beam profile with very little spill over, whereas Optic $B$ has a notable intensity at high angles. This spill beam of light is undesirable since it creates a halo effect around the main beam.

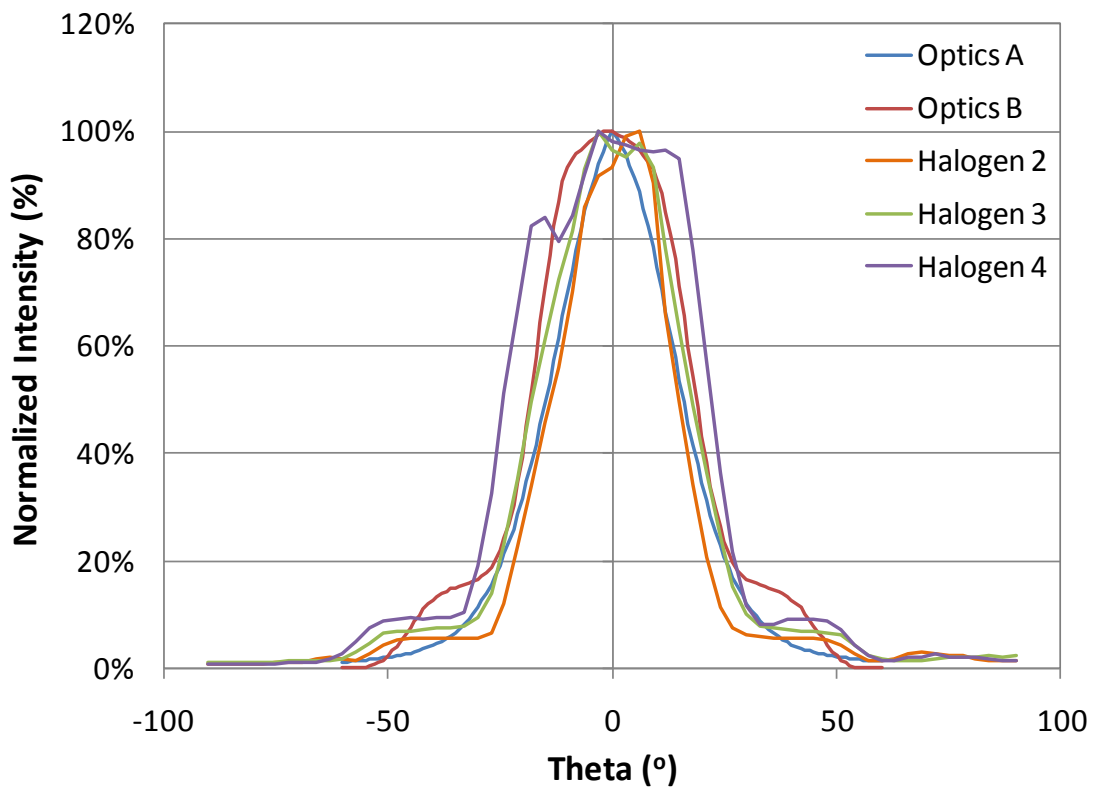

Figure 8: The normalized luminous intensity of halogen lamps as a function of angle is compared to the two promising optics. In general, the spillover from the halogen lamps falls between that of Optic A and Optic B. While efficient, Optic B is not of good enough beam quality to replace a halogen lamp. 
lamps are shown in Figure 8, along with Optics A and B. The amount of spill over varied between the assorted lamps, as well as the quality of the coherent beam. In general, the halogen lamps have a spill beam that falls between Optics A and B.

Cree continued to optimize the trade-off between optical efficiency and beam quality to deliver the best overall lamp prototype. The optical design including source size affects the resulting beam angle and cd/lum. The center-beam candle power (CBCP) to luminous flux ratio indicates how much of the flux generated by the component is actually going into the desired beam angle, and is not being lost as spill light (halo effect). The more light that goes into the center beam, the more efficient the optical design of the luminaire is.

Optic D lens design can be used with different LED source sizes. As the source size increases (more chips or larger chips), the cd/lum ratio decreases but the overall light level, including that in the center beam, goes up. There is a trade-off between the optical source size (and resulting $\mathrm{cd} / \mathrm{lm}$ ) and the overall flux levels needed in the desired footprint of the ultra-compact luminaire.

Optic D, when combined

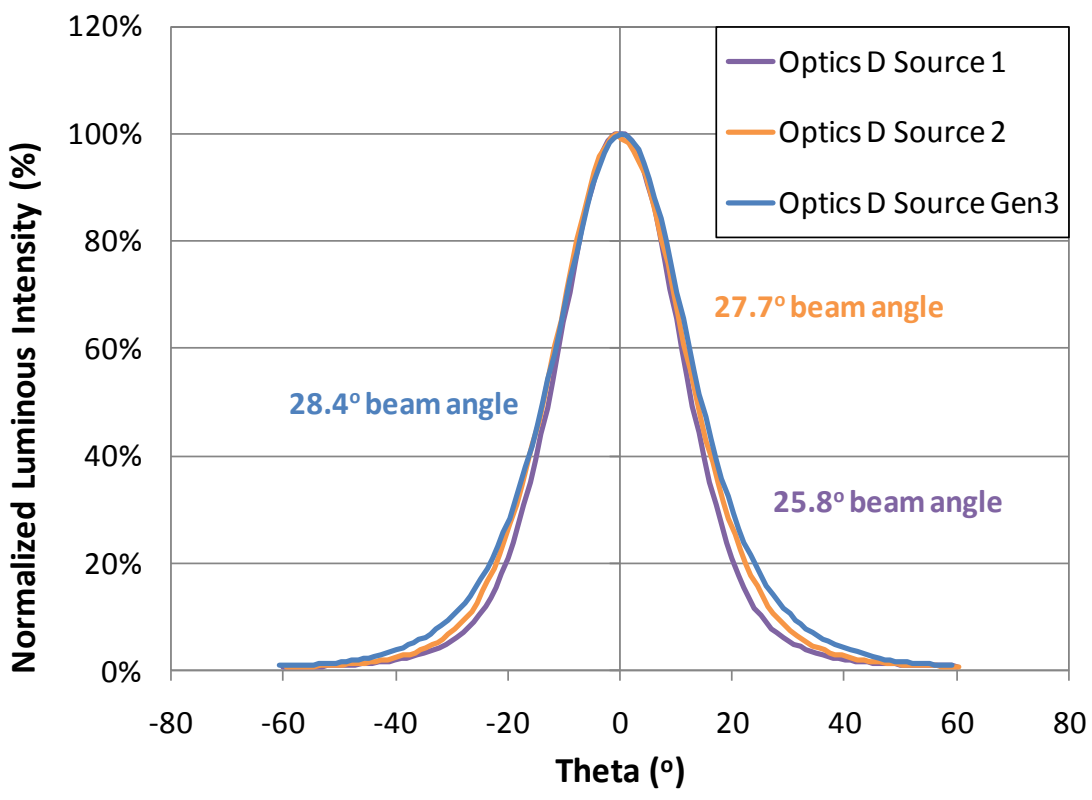

Figure 9: The relative luminous intensity of Optics D with various optical source sizes. As the optical source size increases, the beam is broadened with Source $1<$ Source $2<$ Source 3. The Generation 3 component with Optic D resulted in a beam angle of 28.4 degrees.

with the Generation 3 component, provided $91 \%$ optical efficiency with a beam angle of $28^{\circ}$, as seen in Figure 9. This exceeded the Y1.75 milestone for secondary optic with $\geq 88 \%$ optical efficiency.

\section{SECTION III - Compact Driver Development}

The driver design is dependent on the characteristics of the LED component designed in Task 1 since the chip count and drive conditions affect the optimal solution for high efficiency drivers. Various driver topologies were evaluated for the LED component design by measuring prototype test boards with the desired LED load. Driver efficiencies up to $89 \%$ were 


\begin{tabular}{|c|c|}
\hline Driver Design & Efficiency \\
\hline A & $77 \%$ \\
\hline B & $87 \%$ \\
\hline C & $71 \%$ \\
\hline D & $89 \%$ \\
\hline
\end{tabular}

Table 4: Measured driver efficiency values of four different designs with varying topologies demonstrated on test boards (includes AC-DC conversion). Driver design $\mathrm{D}$ showed the highest efficiency of $89 \%$ and was selected for further development.

demonstrated on prototype boards (AC-DC conversion), as listed in Table 4.

Cree optimized the driver topology D for the Generation 2 component design, with efficiency and dimmability in mind. The driver piece parts were ordered and assembled to fit within the small driver cavity of the ultra-compact luminaire (which leaves the majority of the luminaire envelope for thermal management). The driver was tested in a fully assembled luminaire prototype running at steady-state operation using a prototype LED component, and heat sink.

The LED driver was $85.9 \%$ efficient with a power factor correction of 0.88 in the compact luminaire form factor (Figure 10) meeting the Year 1 milestone of a prototype LED driver with $85 \%$ efficiency. The driver operates properly whether using a magnetic transformer, electronic DC transformer or an electronic AC transformer. The driver was also dimmable and did not lead to any flicker during its full dimming range with the magnetic and electronic DC

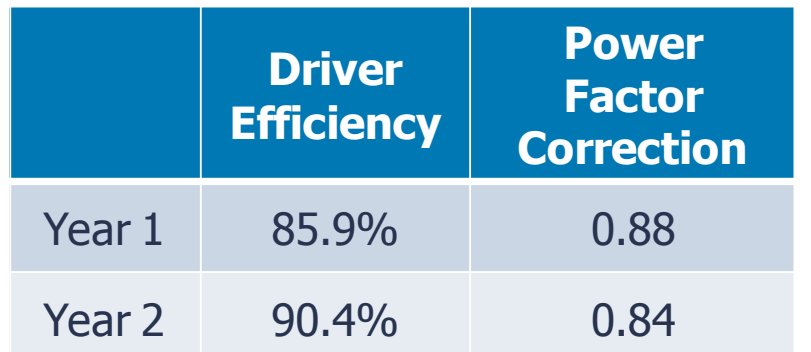

Table 5: The performance of the prototype compact driver is compared for the two project years. By the end of the project a $90.4 \%$ driver efficiency was demonstrated in the luminaire using the Generation 3 LED component developed in Task 1. This meets the Y1.5 driver efficiency milestone.

transformer. Flicker did occur with the electronic AC transformer at low LED loads. Cree will look to make the dimming circuit more robust in the future prototypes.

During the second year, Cree has improved its driver design to be more efficient, while still fitting the small driver cavity in the luminaire. Cree demonstrated an $90.4 \%$ efficient prototype LED driver with a power factor correction of $\mathbf{0 . 8 4}$ in the luminaire form factor, meeting the Year 1.5 milestone of a prototype LED driver with $90 \%$ efficiency. The driver was tested at steady-state operation using a prototype Generation 3 LED component. 


\section{SECTION IV - Luminaire Integration}

The packaged LED component, secondary optics, thermal management and power conversion were combined to build the final luminaire demonstrator. Two different ultra-compact luminaire prototypes $(2800 \mathrm{~K}$ and $3300 \mathrm{~K}$ CCT), with Generation 3 components, were tested at varying current levels to see the range of performance (no driver), as plotted in Figure 10.

At steady-state operation, the 2800K, 94 CRI luminaire generated 360 lumens with an efficacy of 107 LPW at 150 $\mathrm{mA}$ and 695 lumens with an efficacy of $86 \mathrm{LPW}$ at $350 \mathrm{~mA}$ (excluding driver). At $3300 \mathrm{~K}$ and 93 CRI, prototype lamps deliver 763 lumens with 83 LPW at $300 \mathrm{~mA}$ or 463 lumens with $102 \mathrm{LPW}$ at 150 $\mathrm{mA}$ (excluding driver).

The prototype luminaire was then integrated with the high efficiency driver and provided 380 lumens at CCT of $2822 \mathrm{~K}$
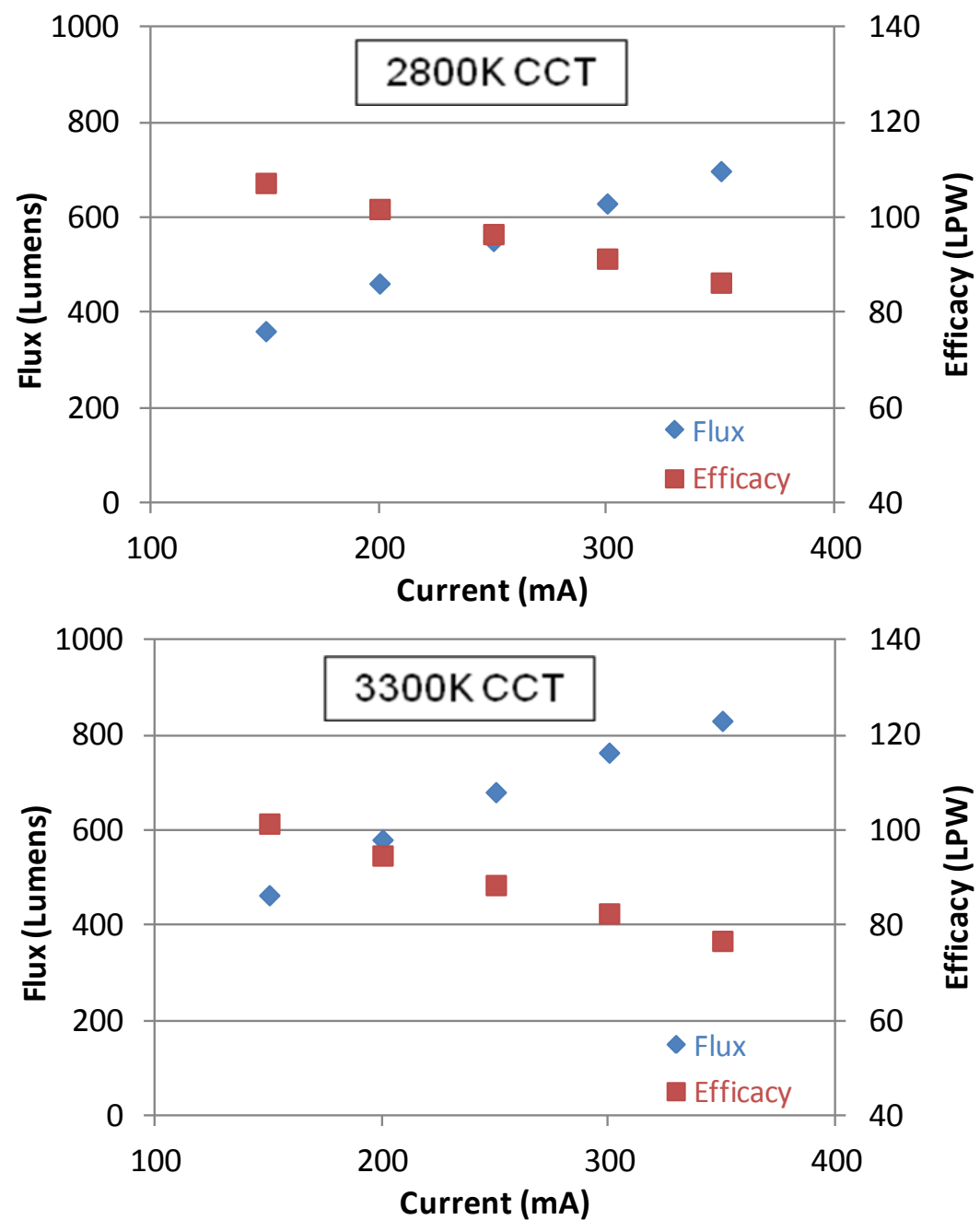

Figure 10: The (excluding driver) flux and efficacy characteristics as a function of drive current are shown for two ultra-compact luminaire prototypes at a CCT of $2800 \mathrm{~K}$ and $3000 \mathrm{~K}$. At steady-state operation, the $2800 \mathrm{~K}, 94 \mathrm{CRI}$ luminaire generated 360 lumens with an efficacy of 107 LPW at $150 \mathrm{~mA}$. At $3300 \mathrm{~K}$ and $93 \mathrm{CRI}$, the luminaire prototype delivered 463 lumens with $102 \mathrm{LPW}$ at $150 \mathrm{~mA}$.

and CRI of 94 with an efficacy

of $94 \mathrm{LPW}$ when operating at $4 \mathrm{~W}$ input power (steady state). The overall system efficiency was $81 \%$. This performance exceeds the Year 2 goal of a proof-of-concept lamp providing 320 lumens and $80 \mathrm{LPW}$ at $3000 \mathrm{~K}$ CCT and CRI $\geq 90$. At a higher input power of $9 \mathrm{~W}$, the lamp provided 658 lumens at 71 LPW. 
LM-79 testing was performed on the 3300K prototype luminaires at Cree's

Durham Technology Center, an NVLAP accredited photometric test laboratory. The $3295 \mathrm{~K}$ prototype luminaire provided 377 lumens and 83 LPW with $90 \mathrm{CRI}$ at an input power of $4.5 \mathrm{~W}$. The normalized luminous intensity distribution (polar plot) of the prototype MR16 lamp provides a $29.2^{\circ}$ beam angle which is within the project target range of $20-40^{\circ}$ (Figure 11).

\section{TECHNOLOGY}

\section{COMMERCIALIZATION}

Cree typically employs a three-tiered commercialization strategy consists of

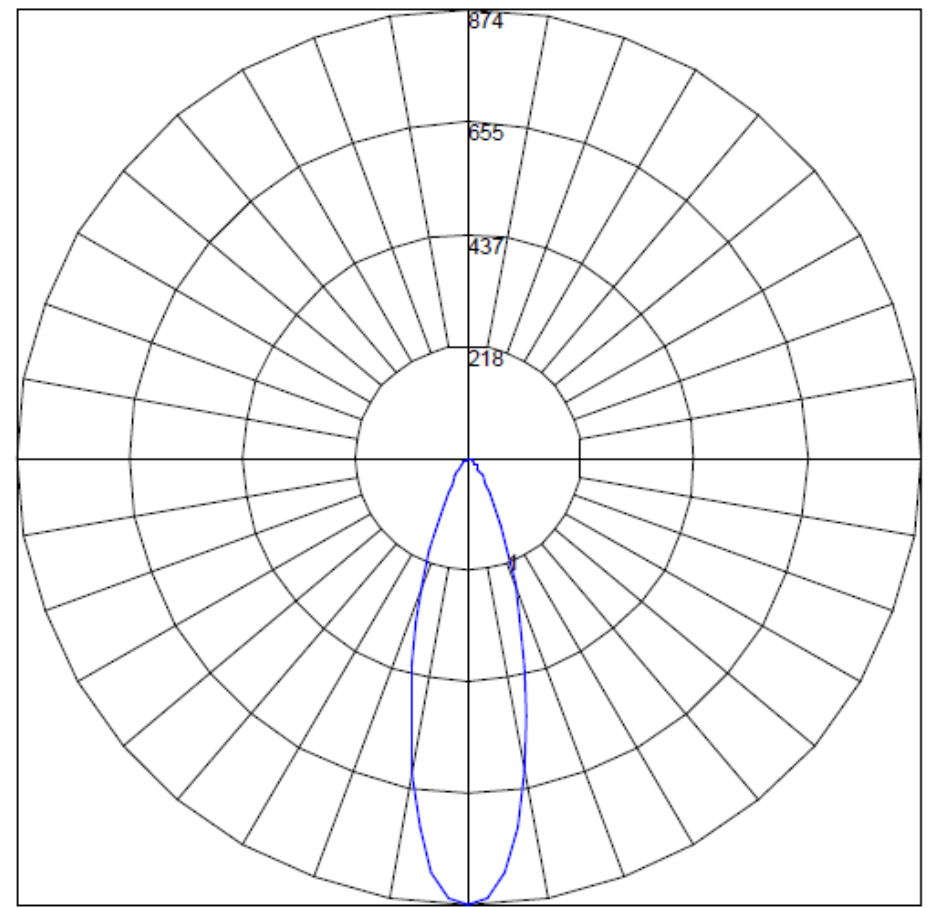

Figure 11: The normalized luminous intensity distribution (polar plot) of the prototype luminaire provides a $29.2^{\circ}$ beam angle which is within the project target range of $20-40^{\circ}$. selling LED chip, LED components and LED luminaire products. Based on Cree's three-tiered SSL business model (Figure 12), we plan to evaluate two potential products from this product development. Cree will review

LED Chips

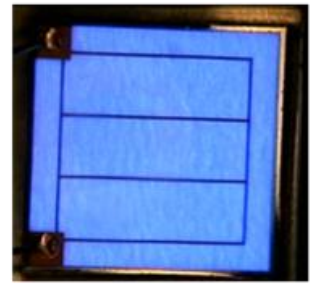

LED Components

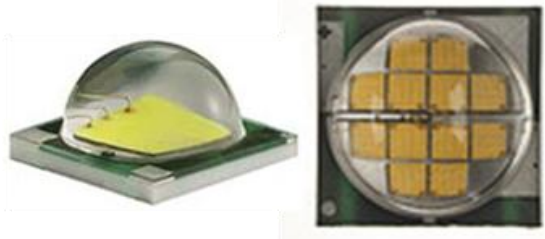

LED Luminaires

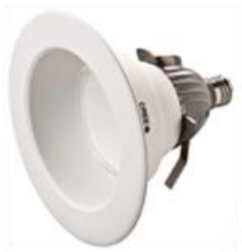

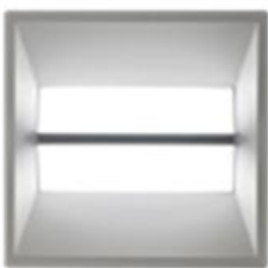

Figure 12: Cree's three-tiered commercialization strategy consists of selling LED chip, LED component and LED luminaire products.

manufacturing and selling the developed LED component to Cree LED Lighting and OEM customers for integration into lighting systems. Cree will also perform a business case assessment of bringing an ultra-compact luminaire to market or supporting our component customers to achieve this goal.

The technology developed under this project will help maintain Cree's leadership in the adoption of LED lighting in general illumination. Products from a growing number of LED 
fixture makers utilize Cree's lighting-class LEDs to deliver real energy savings and economic benefits over a range of general illumination applications, both domestically and internationally.

\section{CONCLUSIONS}

The project's ultimate objective was to produce an 80 LPW ultra-compact LED luminaire that provided 320 lumens at $3000 \mathrm{~K}$ and $90 \mathrm{CRI}$. Cree has successfully completed this project by developing a new LED component and driver design and combining that with optimized secondary optics and thermal designs to enabled an efficient, ultra-compact LED luminaire. The prototype provided 380 lumens at CCT of $2822 \mathrm{~K}$ and CRI of 94 with an efficacy of 94 LPW when operating at $4 \mathrm{~W}$ input power (steady state) with an overall system efficiency of $81 \%$. At a higher input power of $9 \mathrm{~W}$, the lamp provided 658 lumens at $71 \mathrm{LPW}$. 